\title{
Disseminated Intravascular Coagulation: Present and Future Perspective
}

\author{
R. R. de Gopegui ${ }^{1}$, H. B. Suliman ${ }^{2}$ and B. F. Feldman ${ }^{2}$ \\ ${ }^{1}$ Faculty of Veterinary Medicine, Department of Pathology and Animal Production, Autonomous University of Barcelona, Barcelona, Spain; \\ and ${ }^{2}$ Comparative Hemostasis Laboratory, Department of Biomedical Sciences and Pathobiology, Virginia Maryland Regional College of \\ Veterinary Medicine, Virginia Polytechnic Institute and State University, Blacksburg, VA, USA
}

\section{Introduction}

The haemostatic response could be considered a defensive function: it prevents or avoids blood loss from damaged vasculature (haemorrhage) and ensures adequate blood flow, maintaining the vascular tree free of obstruction (thrombosis). Procoagulant activity (inactive haemostatic proteins) is modulated or inhibited by several mechanisms. Endothelial cells play a key role in the control of these functions. The adequate equilibrium between activation and inhibition of haemostasis depends on interactions between endothelial cells, platelets, circulating blood cells, coagulation activators and inhibitors.

Disseminated intravascular coagulation (DIC) may represent loss of haemostatic equilibrium - induced by numerous clinical entities - resulting in life-threatening consequences.

This review summarises the data recently obtained concerning the aetiology, pathophysiology, clinical findings and laboratory diagnostics as regards DIC. Current and future DIC diagnostic and treatment modalities are discussed. It should be realised at the outset that disease presents differently among a continuum of events. Patients may undergo DIC anywhere in this continuum and, depending on the position in the continuum, exhibit radically different clinical and laboratory effects.

Correspondence and offprint requests to: Dr B. F. Feldman, Comparative Hemostasis Laboratory, Department of Biomedical Sciences Virginia Maryland Regional College of Veterinary Medicine, Virginia Polytechnic Institute, Blacksburg, VA 24061-0442, USA.

\section{Terminology}

Disseminated intravascular coagulation (DIC), is also known as consumptive coagulopathy, an inappropriate descriptor because, although some coagulation proteins (factors and inhibitors) are consumed, many factors and other plasma constituents are biodegraded by plasmin (Jandl 1991). Another descriptor, defibrination syndrome, would be more appropriately retitled 'defibrinogenation syndrome', because fibrinogen is both consumed and biodegraded. Therefore, the term disseminated intravascular coagulation is given preference - it describes the dynamic process of disseminated coagulation taking place intravascularly - expressed as both haemorrhage and thrombosis (Feldman 1981; Slappendel 1988b). DIC is obviously expressed by haemorrhagic diatheses. But, DIC is also associated with diffuse thrombosis (and is sometimes called diffuse intravascular thrombosis; DIT) leading to impairment of blood rheology, ischaemia and multiorgan failure, perhaps causing irreversible damage and, ultimately, patient mortality.

\section{Aetiology}

DIC is associated with numerous clinical conditions (Table 1). Depending on the activation rate of the haemostatic system, DIC may occur as an acute and lifethreatening event or as a chronic form without severe thrombosis and haemorrhage. DIC may be initiated by a single cause or by multiple causes occurring sequentially or simultaneously. The anticipated events inducing DIC - in most conditions - are related to: 
Table 1. Conditions associated with disseminated intravascular coagulation

\begin{tabular}{ll}
\hline A. Intravascular haemolysis & G. Malignancy (Table 3) \\
Haemolytic transfusion reactions & H. Massive tissue injury \\
Haemolytic anemia & Trauma \\
B. Septicaemia (Table 2) & Burns \\
Gram negative (endotoxin) & Surgical procedures \\
Gram positive (bacterial coat & Heat stroke \\
mucopolysaccharide) & I. Venoms and Toxins \\
C. Viraemia (Table 2) & Snake bite \\
D. Parasitic infections & Bee/insect sting \\
Protozoal infection & Aflatoxin (see J.) \\
Metazoal infection & J. Liver disease \\
E. Obstetric complications & K. Pancreatitis \\
F. Miscellaneous & \\
Gastric dialtation/volvulus & \\
Diabetes mellitus &
\end{tabular}

1. Tissue factor (TF) or thromboplastin-like substances liberated into the circulation;

2. Damaged endothelia/monocytes converting procoagulants into active forms (activated procoagulants);

3. Blood flow interruption preventing hemodilution of activators;

4. Impaired removal of activated procoagulants by the liver.

\section{Intravascular Haemolysis}

Intravascular haemolysis is a considerable trigger for DIC. The acute haemolytic transfusion reaction represents a major DIC stimulus. The release of erythrocytic adenosine diphosphate (ADP) and/or membrane phospholipoproteins may directly stimulate platelet aggregation and coagulation (Bick 1985; Borrego et al. 1991). Even transfusion of autologous haemolysed blood was found to cause decrease in factors X, VIII, fibrinogen and to cause pulmonary arterial thrombosis in dogs (Cotter 1992).

\section{Infectious Agents}

DIC has been reported in association with many infectious agents (Table 2) including numerous Gramnegative and Gram-positive organisms (Stein and Libertin 1990; Morris 1991). Bacterial coat lipopolysaccharide (LPS) released as a result of proliferation or lysis of Gram-negative bacteria (endotoxin), has the ability to initiate DIC (Warr et al. 1990) by direct activation of endothelium, the contact system (the kinin system and factors XII and XI), complement, leucocytes and platelets (Ewert et al. 1985; Moher 1988). Gram-positive bacteria have mucopolysaccharide coats which may induce DIC by the same mechanisms noted with endotoxins. Septicaemia due to bacterial infection
Table 2. Bacteria and viruses incriminated in disseminated intravascular coagulation

\begin{tabular}{ll}
\hline Bacteria $^{a}$ & Viruses $^{\mathrm{b}}$ \\
\hline $\begin{array}{l}\text { Gram-negative bacteria } \\
\text { Escherichia coli }\end{array}$ & Infectious canine hepatitis \\
Pasteurella hemolytica & Canine distemper \\
Pasteurella multocida & Canine herpes virus \\
Salmonella species & Feline infectious peritonitis \\
Gram-positive bacteria & Feline panleukopenia \\
Staphylococcus species & Hog cholera \\
Streptococcus species & African swing fever \\
Clostridium species & Blue tongue \\
Mycobacterium species & Epizootic haemorrhage of deer \\
& Fowl plague \\
& Viral haemorrhagic disease of \\
\hline
\end{tabular}

'Ellison et al. (1988), Kiper and Paulsen (1988), Isogai et al. (1989), Bowersock et al. (1990), Braun et al. (1990), Kokosharov et al. (1990), Stein and Libertin (1990), Morris (1991), Anderson et al. (1992).

${ }^{b}$ Ward and Conway (1980), Howerth et al. (1988), Pan et al. (1988), Greene (1990), Greene and Scott (1990), Huang (1991).

is accompanied by acidosis which may provide an independent trigger for DIC (Bick 1985). However, the clinical presentation is probably the summation of several or all of these activation events.

\section{Viruses}

Viruses responsible for triggering DIC may do so by involvement in associated circulating antigen-antibody complexes which activate the endothelium and possibly the contact system. Viruses can also induce the platelet release reaction (Bick 1985; Cosgriff 1989; Studdert 1994).

\section{Parasitic Infections}

Protozoal infections such as trypanosomiasis (Olubayo and Mugera 1985; Suliman and Feldman 1989), babesiosis (Krooshof et al. 1984; Blood and Radostits 1989), and sarcocystosis (Frelier and Lewis 1984; Daugschies et al. 1989) may induce DIC.

Metazoal infection associated with DIC is exemplified by heartworms in dogs (Dillon and Braund 1982). The vascular damage induced by these blood parasites and the associated embolic phenomena causes release of tissue thromboplastin, the key to triggering DIC in heartworm patients (Kociba and Hathaway 1974; Cooley et al. 1987).

\section{Obstetric Complications}

Obstetric complications commonly trigger DIC (Seegers 1971). DIC may occur in association with dystocia, eclampsia, Caesarean section, and retained 
fetal placenta (Dodds 1985; Braun et al. 1990). A physiological potential hypercoagulable state has been reported to be associated with parturition (Murano and Bick 1980; Gentry et al. 1991). The proposed mechanisms that initiate DIC in obstetric complications include: (1) the release of amniotic fluid (with activity similar to thromboplastin, platelet factor 3 or phospholipoprotein into maternal circulation) (Lockwood et al. 1991; Parihar et al. 1991); (2) release of placental enzymes or tissues with thromboplastin-like activity into the maternal circulation (Bick 1985; Braun et al. 1990; Wagner et al. 1990; Suchartwatnachai et al. 1991); and (3) release of necrotic fetal tissue or enzymes (with activation of the maternal haemostasis) into the maternal circulation (Angelov 1989; Bosner et al. 1989; Braun et al. 1990).

\section{Miscellaneous}

DIC has been identified as an important complication that affects both mortality and morbidity in gastric dilatation-volvulus patients (Drazner 1982). The damaged organs release large amounts of thromboplastins into the circulations; local acidosis may occur leading to DIC (Hall 1972; Lippincott and Schulman 1989). Acidosis triggers DIC through sloughing of endothelial cells and subsequent activation of the contact system (Baker 1989).

In diabetic patients DIC may be initiated by injury of the vascular endothelium (Bick 1979), peripheral capillary stasis (Bick 1982, 1985), microangiopathy, and enhancement of platelet aggregation (Titova et al. 1989; Barnett 1991).

\section{Malignancy}

Malignancy is reported as the underlying disease in $39 \%$ of dogs diagnosed with DIC (Feldman et al. 1981). Haemangiosarcoma, disseminated carcinomas, haematopoietic and lymphoreticular tumours are commonly associated with DIC in small animals (Helfand 1988; Hammer et al. 1991; Hargis and Feldman 1991). DIC has been suggested as the major pathophysiological mechanism underlying microangiopathic haemolytic anaemia (MAHA) often associated with malignancy in small animals (Helfand 1988; Slappendel 1988a). The presence of large tumour burdens or tumours associated with bone marrow, spleen or liver (specifically widespread infiltration - haemangiosarcoma, lymphosarcoma or leukaemia) are conditions associated with MAHA in dogs (Madewell and Feldman 1980; Rebar et al. 1980). There are five possible mechanisms that trigger DIC in cancer patients and these are listed in Table 3. Some cancer patients develop typical DIC with secondary fibrinolysis and/or primary activation of fibrinolysis that overwhelms the fibrinolytic inhibitor response. In cancer patients, subclinical compensated DIC is more common than either compensated DIC
Table 3. Mechanisms that incite disseminated intravascular coagulation in cancer patients

1. Stimulation of the coagulation cascade

(a) Cancer cells induce platelet activation and aggregation (Hammer et al. 1991; Hargis and Feldman 1991; Suchartwatnachai et al. 1991).

(b) Cancer cells release thromboplastin and/or other procoagulant factors (PCA) that enhance coagulation (Madewell and Feldman 1980 Helfand 1988; Slappendel 1988a).

(c) Cancer cells stimulate macrophages and monocytes to release PCA factors (Rebar et al. 1980; Radomski et al. 1991).

(d) Cancer cells release a specific factor $\mathrm{X}$ activator, a cysteine protease known as cancer PCA factor which is released by a variety of malignant cells including breast, liver, renal and, lung carcinomas, undifferentiated sarcomas, liposarcomas, melanomas (Edwards et al. 1990; Spearman et al. 1991).

(e) Non-enzymatic activation of factor $\mathrm{X}$ by the sialic moiety of mucin in mucinous adenocarcinomas (Mohanty et al. 1991).

2. Vascular damage by neoplastic growth or vascular damage of vessels within neoplastic tissues might lead to exposure of subendothelial collagen (Rebar et al. 1980).

3. Enhancement of the haemostatic system by complications of malignancy such as surgery, chemotherapy and sepsis (Rebar et al. 1980).

4. Decrease hepatic synthesis of antithrombin III (AT III), and protein $C$ in metastatic cancer (Gordon 1984; Clouse and Comp 1986; O'Keefe and Couto 1988; Lefrere et al. 1989; Roncaglioni et al. 1989; Clauss et al. 1990; Irimura et al. 1990; Kubota et al. 1991).

5. Activation of the fibrinolytic cascade by a plasminogen activator (urokinase-like) (Clauss et al. 1990) or a tissue-type plasminogen activator released from some tumour cells (Jones et al. 1980; Giger and Gorman 1984; Badenoch et al. 1986; Camiolo and Greco 1986; Kapina et al. 1986; Duffy 1990; Reilly et al. 1991).

with thrombosis or uncompensated DIC leading to haemorrhage (Madewell and Feldman 1980; Giger and Gorman 1984). Haemorrhagic DIC has been seen with various tumours including thyroid carcinoma, haemangiosarcoma, mammary carcinoma, intrathoracic carcinoma, and adrenal tumour (Jones et al. 1980; Green 1981; O'Keefe and Couto 1988). In contrast to humans, DIC appears to be uncommon in dogs with leukaemia. It has been suggested that DIC may complicate leukaemia in cats (Kobilinsky et al. 1979; Jacobse-Geels et al. 1980).

\section{Traumatic Shock}

Traumatic shock is a well-recognised cause of DIC (Hardaway 1981; Ordog and Wasserberger 1986). Thromboplastic substances are released from traumatised tissue into the circulation, precipitating the development of DIC. In addition, the decreased flow of capillary blood induced by hypovolaemia is a contributing factor (Hardaway 1980a,b). Clinical and laboratory evidence indicate that the passage of blood through traumatised tissue causes erythrocyte lysis triggering coagulation (Hardaway and Williams 1987, 1990). The release of cellular enzymes in combination vasoactive substances already in the circulation also contribute to 
the induction and perpetuation of DIC (Hardaway 1980a; Ordog and Wasserberger 1986; Hardaway and Williams 1990). As the fibrinolytic system is also activated both microthrombi and haemorrhage may be observed (Hardaway 1981).

DIC may occur subsequent to bone fracture and fracture surgery. The direct release of large amounts of lipids and tissue thromboplastin from fractured bones into the circulation initiates hypercoagulability in some patients (Buntain 1980; Raphael 1982). All surgical procedures activate the haemostatic system. This is especially true of prolonged abdominal surgical procedures (Buntain 1980; Lipowitz 1985).

Thermal injuries are relatively uncommon in domestic animals, especially large animals. Severely affected patients commonly develop DIC, with several mechanisms operative (Johnston 1985; Iashvili et al. 1986; Ono 1987). DIC in burned animals presumably results from both haemolysis and tissue necrosis and release of tissue components, cellular enzymes, and phospholipoprotein-like materials into the circulation (Bick 1982). The aetiology of DIC in the early stages after thermal injury remains unclear. However, massive thrombin generation and decrease of anticoagulant activity, mainly antithrombin III (ATIII) concentrations, have been observed (Goodwin 1989; Ueyama et al. 1991).

Heat stroke can directly provoke DIC by widespread vascular and tissue damage (Drazner 1982; Holman and Schneider 1989).

\section{Liver Disease}

Development of DIC is a common event in severe hepatopathy in dogs and cats (Green 1989). Impairment of hepatic synthesis of coagulation proteins or impaired hepatic clearance functions may manifest as thrombotic, fibrinolytic or haemorrhagic complications (Hersch et al. 1987; Green 1989). The enhanced plasmin generation noted in liver disease promotes activation of the kinin system causing hypotension, shock and end-organ damage, as well as biodegradation of coagulation factors by plasmin (Kaplan and Silverberg 1987). Failure of clearance of fibrin(ogen) degradation products (FDPs) by the diseased liver will allow FDPs to further impair fibrin polymerisation and platelet aggregation (Drazner 1982). Ingestion of aflatoxin contaminated dog food has been reported to cause DIC (Hagiwara et al. 1990). The resultant severe hepatocellular degeneration and necrosis is sufficient to initiate DIC through extensive release of tissue thromboplastin (Baker and Green 1987).

\section{Venoms and Toxins}

Snake venoms contain enzymes that may trigger haemostasis in unique ways. Venoms contain thrombinlike enzymes or substances that specifically activate factor X (Bothrops atrox) or factor II (Wintrobe et al. 1981). Echis carinatus venom was found to rapidly induce DIC in mongrel dogs by direct activation of prothrombin (Schaeffer et al. 1986). The venom of Pseudonaja textilis textilis - an Australian snake contains prothrombinase. This converts prothrombin into $\alpha$-thrombin directly, resulting in fibrinogen degradation (Masci et al. 1990). Crude venoms also contain substances that act as thromboplastins and produce intravascular red cell lysis and massive vascular endothelial damage (Wintrobe et al. 1981). Hymenoptera (bees, wasps and hornets) stings in dogs result in acute DIC which can be fatal, or more chronic forms of DIC (Cowell et al. 1991). DIC is initiated by Hymenoptera venom which includes components such as phospholipase A, histamine, acetylcholine, serotonin and kinins.

\section{Pancreatitis}

Pancreatitis may trigger DIC by activation of trypsin, kallikrein $(\mathrm{KK})$ and phospholipase $A_{2}$ in the pancreatic (and surrounding) tissue (Uehara et al. 1989; Williams 1989). These enzymes have thrombin-like activity or factor Xa-like activity which results in activation of the haemostatic system and DIC. The release of leucocyte elastase during pancreatitis has the capacity to degrade plasma proteins such as $\alpha 2$-antiplasmin, ATIII and factor XIII. This protein degradation may cause more tissue damage and can further potentiate DIC (Axelsson et al. 1990).

\section{Pathophysiology (Fig. 1)}

Disseminated intravascular coagulation may be considered an uncontrolled burst of thrombin generation and activity. This massive activation overwhelms haemostatic inhibitors, depletes procoagulants and platelets, induces thrombosis, and as a final result tissues are severely damaged. Thrombus formation and subsequent ischaemia and necrosis may activate an enhanced fibrinolytic response which would impair platelet function and deplete coagulation factors (Schrier 1993).

The inflammatory response has important interactions with haemostasis, may activate haemostasis or impair its inhibition. Recent studies, have described some of these interactions.

1. Neutrophil activation and degranulation liberates lactoferrin, a prominent component of neutrophil secondary granules. Lactoferrin is an iron-binding protein and thus has a physiological role in the regulation of inflammation and other host defence mechanisms. Lactoferrin has potent heparin-neutralising activity during thrombin inhibition by serine proteinase inhibitors ATIII and heparin cofactor II. It has been observed that specific inflammatory mediators as tumour necrosis factor- $\alpha$ (TNF- $\alpha$ ) increased the concentration of both platelet factor 4 (PF-4), which inhibits 


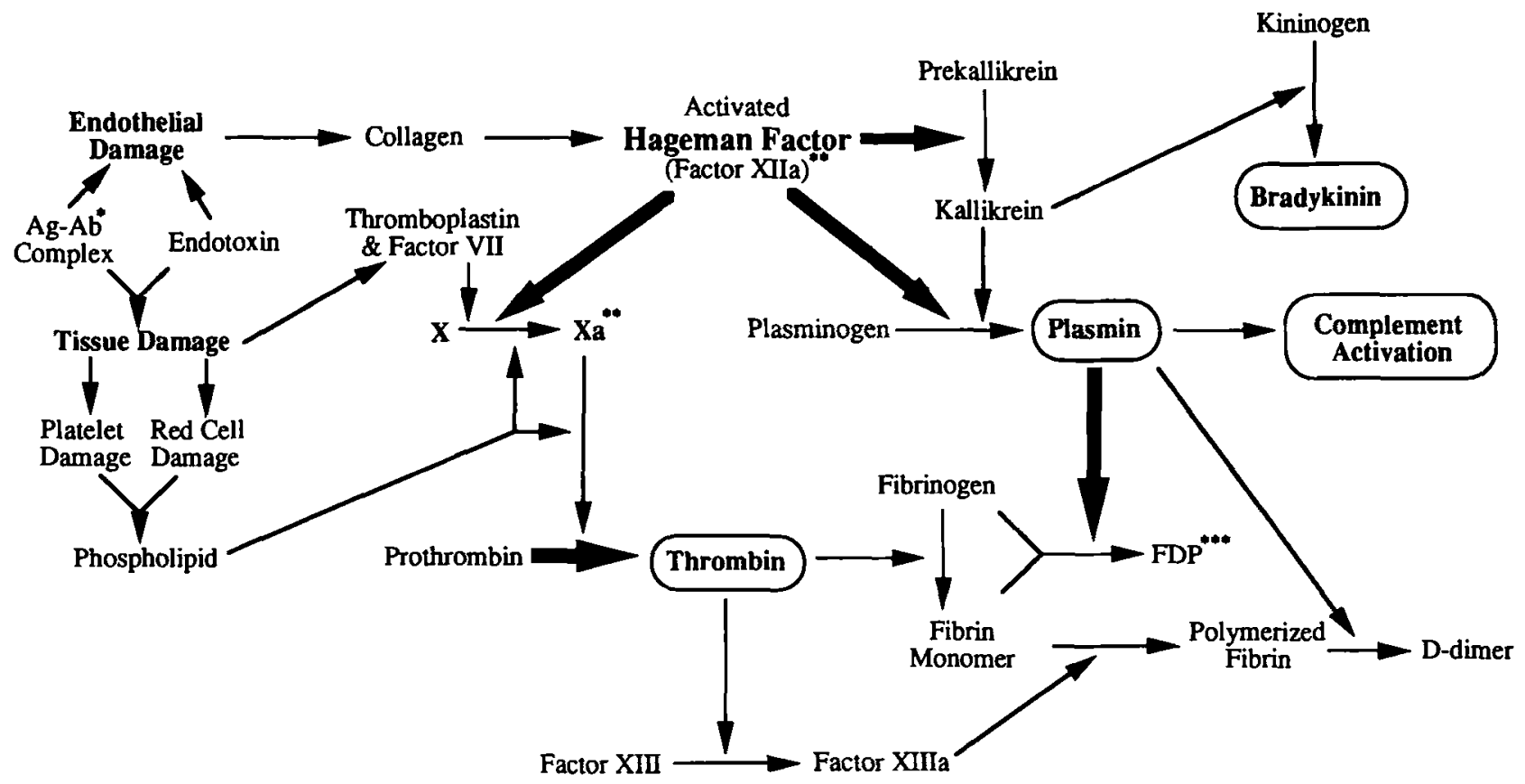

Fig. 1. Pathophysiology of disseminated intravascular coagulation (DIC). * Antigen-antibody complex; ${ }^{* *}$ Activated factor; ${ }^{* * *}$ Fibrin(ogen) Degradation Products.

heparin, as well as plasma lactoferrin (Wu et al. 1995). Activated neutrophils adhere to endothelium and release elastase which cleaves and may inactivate thrombomodulin (TM) (Esmond 1994). Platelet aggregation may be induced by activated neutrophils, mediated by platelet activating factor-acether (PAFacether). PAF is a phospholipid produced by vascular endothelium, platelets and monocytes (Nguyen et al. 1995).

2. The cytokines TNF- $\alpha$ and interleukin 1 (IL-1), may initiate the endothelial expression of adhesion molecules (one of which is E-selectin; others have yet to be identified) that bind monocytes and neutrophils. Pselectin requires thrombin activation to be mobilised from endothelial Weibel-Palade bodies. This fact may involve platelet adhesion to endothelial cells and monocytes, and could serve as a focal point to amplification reactions involved in thrombin generation (Edmond 1994).

3. Complement terminal components C5b-9, induce a procoagulant activity in platelets. Coagulation factors can adhere to negatively charged phospholipids such as phosphatidylserine, which normally, is not exposed on the surface of inactivated platelets. It is suggested that platelet activation may induce membrane vesiculation and formation of microparticles. This may be considered a critical component of prothrombin activation (Esmond 1994; Sandberg et al. 1985).

The contact system includes factors XII (FXII) and XI (FXI) and the kinins. Activation of the contact system occurs through contact with negatively charged surfaces, cerebroside sulphates, glycosaminoglycans, plasmin, hypersensitivity/anaphylactic reactions, and lipid A component of endotoxins (Wachtfogel et al. 1993). The consequences are:

1. Coagulation factors VII and XI are activated (by FXIIa);

2. Complement fraction $\mathrm{C} 1$ is activated (by FXIIa);

3. Prourokinase and plasminogen are activated by FXIIa and kallikrein;

4. Neutrophils are activated by FXIIa and kallikrein;

5. Kininogens increased the activation of FXI, but inhibit cellular adhesion to endothelium (monocytes, neutrophils and platelets). In addition, bradykinin increases vascular permeability and hypotension.

Endothelial cells and monocytes may express tissue factor when these cells are exposed to endotoxins, IL-1 and TNF (Esmond 1994). The formation of factor VIITF complexes induces factor $\mathrm{X}$ and factor IX activation. The inhibitory activity of tissue factor pathway inhibitor (TFPI) may possibly be overwhelmed if TF exposure is extensive. Furthermore, the experiment administration of human recombinant TFPI in animal models of endotoxin-induced shock reduced mortality. The inhibitory activity of TFPI on inflammatory response is also suggested because lower concentrations of IL-6, were found in these animals (Taylor 1994; Petersen et al. 1995).

Endothelial damage caused by circulating antigenantibody complexes, endotoxaemia, or other forms of tissue damage can change the endothelial cell anticoagulant phenotype. This results in a massive procoagulant fibrinolytic counterattack on the luminal side of the endothelial cell through the expression of TF and release of tissue plasminogen activator (tPA) (Taylor 1994). Trauma and haemolysis may also liberate TF into 
the circulation (Mant and King 1979; Slappendel 1988b; Muller 1989; Nakamura et al. 1990). When one of these insults occurs, there are many potential elements for uncontrolled generation of circulating thrombin and plasmin. Circulation of these two enzymes systematically may be considered DIC. Despite the differing activation pathways by which thrombin and plasmin are generated, the resultant pathophysiology of DIC basically remains the same (Mant and King 1979; Slappendel 1988b).

Thrombin activates the protein $C$ pathway. The early activation of protein $C$ (and subsequent consumption) in-sepsis has been observed in human patients. Thrombin bound to TM - an endothelial cell surface receptor activates protein $C$, and results in feedback inhibition of thrombin (thrombin loses its coagulant effect). Activated protein C (APC) bound to the cofactor protein S, cleaves FVa and FVIIIa. Protein S circulates free or bound to $\mathrm{C} 4 \mathrm{~b}$ binding protein $(\mathrm{C} 4 \mathrm{bBP})$, an inhibitor of complement (and at the same time an inhibitor of the protein $\mathrm{C}$ pathway). Activated $\mathrm{PC}$ is inhibited by protein $\mathrm{C}$ inhibitor (PCI) - a heparin-dependent reaction - and $\alpha 1$-antitrypsin. Protein $C$ inhibitor also binds KK. KK may also play a regulatory role in protein C activity (Alcaraz et al. 1995). The effect of cytokines on the protein $\mathrm{C}$ pathway has been studied, especially related to septic shock. It has been observed that infants with protein $\mathrm{C}$ deficiency may develop purpura fulminans. Patients with severe septic shock present with similar cutaneous lesions which resemble this process (Walsh et al. 1991). Thereafter, C4bBP behaves as an acute phase reactant which can reduce free protein $S$ concentrations (Esmond 1994). Endotoxins and cytokines (IL-1 and TNF) also downregulate TM expression (Edmond 1994). In conclusion, coagulation inhibition is severely impaired potentiating thrombus formation.

Thrombin activates FV, FVIII:C and FXIII and cleaves fibrinopeptides $A$ and $B$ from fibrinogen to yield fibrin monomers. The monomers polymerise into fibrin clots. This leads to microvascular and macrovascular thrombosis and ensuing ischaemia and organ failure (Muller 1989; Jandl 1991). Thrombin also binds irreversibly to platelets promoting platelet adhesion to endothelial cells, platelet aggregation, and induces secretory release of platelet $\alpha$ and dense granule contents (Nomura et al. 1991; Venturini and Kaplan 1992). ADP and thromboxane $A_{2}\left(T_{x} A_{2}\right)$ release will further accelerate platelet aggregation causing amplification of coagulation processes and thrombin generation. Platelets are trapped in micro- or macrothrombi. This results in the clinical manifestations of thrombocytopenia (Feldman 1981; Feldman et al. 1988; Jandl 1991).

Plasmin is generated by the enzymatic conversion of circulating plasminogen (a proenzyme, synthesised by kidneys, liver and eosinophils). Tissue PA is secreted by injured endothelium and macrophages near the injured area, and contact system activation also contributes to plasmin generation. Plasmin is capable of hydrolysing not only fibrin and fibrinogen but also other proteins such as factors V, VIII, IX, XI, insulin, ACTH, casein and gelatin (Muller 1989; Jandl 1991). Digestion of fibrinogen by plasmin results in fibrin(ogen) degradation products (FgDP) composed of fragments X, Y, $D$ and $E$ (Muller 1989). FDPs in the circulation interfere with fibrin monomer polymerisation (basically by inhibiting fibrin polymerisation and blocking the receptor sites of fibrinogen on thrombin) causing further amplification of fibrinolysis, impairment of haemostasis and, resultant haemorrhage (Feldman 1981; Muller 1989; Jandl 1991). Other FDPs (fragments $\mathrm{D}$ and $\mathrm{E}$ ) have high affinity for platelet membranes, inducing platelet dysfunction through granule release and platelet aggregation inhibition (Wintrobe et al. 1981). This contributes to clinical haemorrhage. Thus, systemic release of FDPs in large quantities also contributes to some of the bleeding problems encountered in patients with DIC. Plasmin is capable of activating the complement system ( $\mathrm{C} 1$ and $\mathrm{C} 3$ ), and contributes to the activation of the contact system. Subsequent neutrophil activation, red cells lysis, platelet activation and/or lysis results (Muller 1989; Carroll et al. 1990; Nomura et al. 1991). Damage to both red cells and platelets provides more substrate in the form of procoagulant materials accentuating thrombocytopenia. Activation of the complement system and BK affects the endothelium, enhancing vascular permeability ultimately leading to hypotension and shock.

In summary, inflammation activates haemostasis through neutrophil activation (inducing platelet aggregation, inactivation of heparin-dependent serine proteases and the protein $\mathrm{C}$ pathway), monocyte expression of TF, complement activation (inducing platelet procoagulant activity) and cytokine release (which induces endothelial TF expression and endothelial changes more receptive to coagulation).

Activation of the contact system has several consequences: coagulation activation, activation of fibrinolysis, complement activation, neutrophil activation, and kinin activation. Kinin activation may inhibit adhesion of neutrophils, monocytes and platelets to endothelium, increasing vascular permeability.

If these activation mechanisms overwhelm haemostatic inhibitors and thrombin formation is uncontrolled, thrombus formation is potentiated and subsequent organ failure may develop.

Thrombus formation, contact system activation and endothelial leasin (liberating tPA) all activate fibrinolysis. If plasmin activation is extensive, some coagulation factors are severely depleted.

\section{Clinical Findings}

Although the classic presentation of DIC may include fever, acidosis, hypoxaemia, proteinuria, bleeding, shock and evidence of multiple organ failure (Bick 1985; Slappendel 1988b), it is essential to note that there is considerable variability in clinical findings. DIC can be 
acute or chronic depending on whether the underlying illness is acute (decompensated DIC) or chronic (compensated DIC). The clinical manifestations may also differ among diseases, from patient to patient, and even chronologically in the same patient. Physical findings that accompany microthrombosis-associated DIC are associated with decreased organ perfusion. Renal thrombosis leads to severe renal dysfunction, common sequelae in horses with DIC (Carlson 1990). Gastrointestinal thrombosis results in acute colic secondary to submucosal necrosis and ulceration, a severe complicating event in equine patients with primary gastrointestinal disease. This results in spontaneous gastrointestinal haemorrhage clinically expressed as gross or occult faecal blood (Carlson 1990). In acute DIC, bleeding may occur at puncture sites, intravenous catheter sites, and surgical wounds (Bick 1982; Morris 1988; Carlson 1990). Large vessel bleeding sites are particularly prone to haematoma formation. The resulting pressure on other vital tissues may compound the clinical problem (Ampel et al. 1985). Prominent clinical manifestations in horses are the tendencies to major vessel thrombosis, especially after catheterisation, and thrombosis of smaller cutaneous blood vessels manifested by arborising subcutaneous 'cords' (Morris 1988). Melena or haematochezia are seen mostly in ruminants and dogs with DIC (Slappendel 1988b; Carlson 1990). Digital ischaemia, subsequent to microthrombosis, frequently accompanies DIC in horses and plays a key role in the development of laminitis (McClure and McClure 1982; Holland et al. 1986). Pulmonary function may also be compromised by microvascular thrombosis in DIC, causing tachypnoea and hypoxaemia. Cerebral microvascular thrombosis might lead to altered consciousness, convulsion and/or coma (Carlson 1990). Compensated DIC develops in patients with illness that produces a low-grade or intermittent procoagulant release stimulus. This allows longer time periods during which consumed or degraded coagulants, anticoagulant proteins, and platelets may be replenished. This compensated state may become unbalanced by stress, concurrent diseases, or worsening of the primary disease. Veterinary clinicians rarely see patients in the early phases of DIC. Fulminant DIC is more likely with resultant poor prognoses.

\section{Laboratory Findings}

Laboratory results vary according to the underlying cause of DIC and the evolution of the process. Many newer analytes have become available for evaluating patients with DIC; however, many of these are not, as yet, validated for veterinary use. The diagnosis of DIC cannot be achieved with a single test result and it is not possible to define which alterations are pathognomonic for DIC. But, the tests described below are helpful to diagnose DIC and to monitor therapy.

\section{Red Cell Fragmentation}

Schistocyte or fragmentocyte formation is usually abundant in patients with low-grade DIC, but as only occasionally seen in fulminant DIC. The presence of fragmentocytes may also be seen in a variety of conditions such as MAHA, Heinz body anaemia, iron deficiency, and may even be seen as spurious finding of blood smear preparation (Slappendel 1988b).

\section{Thrombocytopenia and/or Thrombopathia}

The platelet count is typically decreased in DIC; though the percentage decrease may be quite variable. Platelet counts are often elevated as a non-specific inflammatory response. Decreased platelet numbers may, therefore, be relative. Platelet function tests including the template bleeding time and platelet aggregation are abnormal, as a late stage finding in patients with DIC. Therefore, platelet function in DIC patients may be variable (Bick 1988; Muller 1989). Increased platelet turnover and decreased survival is common with DIC patients; platelet factor $4, \beta$ thromboglobulin, and $\mathrm{TxA}_{2}$ concentrations are markers of overall platelet reactivity and release. These concentrations are usually elevated in DIC patients (Bick 1988).

\section{Tests of Secondary Haemostasis}

The prothrombin time (PT) is anticipated to be prolonged in DIC for multiple reasons. The PT depends upon the ultimate conversion of fibrinogen into fibrin. In DIC there is usually consumption-induced hypofibrinogenaemia and increased FDPs, which interfere with fibrin monomer polymerisation. Also lysis of factors $\mathrm{V}$ (and numerous other factors) by plasmin could prolong the PT. However, a PT within the reference interval in DIC patients may be observed as the underlying process progresses from peracute to acute; PT changes from a shortened test - activation of factors $\mathrm{X}$ and prothrombin (II) - through the reference interval and, finally, becoming prolonged.

The activated partial thromboplastin time (APTT) is also anticipated to be prolonged in fulminant DIC because of plasmin-induced biodegradation of coagulation factors. However, APTT may not be prolonged in DIC patients for the same reasons mentioned above in reference to $\mathrm{PT}$.

Thrombin time (TT) or Reptilase time, tests of the final common coagulation pathway, are anticipated to be prolonged in DIC. Both tests may be prolonged by circulating FDPs and subsequent interference with fibrin monomer polymerisation (Jandl 1991). Appropriate results for these tests can be observed in DIC patients when FDP accumulations are a relatively late happening.

Coagulation factor assays provide insufficient clinically useful information in patients with DIC (Feldman 
1981). Fibrinogen concentration is dramatically decreased in patients with fulminant DIC (Feldman 1981). However, normal or elevated concentrations may be seen in patients with early and compensated DIC - where fibrinogen production exceeds degradation (McKay 1983). In addition, most of the underlying disease processes are actively inflammatory (Feldman 1981; Slappendel 1988b). This results in elevated concentrations of fibrinogen early in the process. Fibrinogen concentration is not reliable for diagnosis of DIC in horses, since horses rarely develop hypofibrinogenaemia (Johnstone and Crane 1986). However, return of fibrinogen concentration in other species towards the reference interval may be the best prognosticator of therapeutic success.

\section{Thrombin Activation}

Coagulation activation markers as thrombin-antithrombin III complexes (TAT) are widely used in human medicine to observe thrombin activation in hypercoagulable state (Asakura et al. 1991). ThrombinATIII complex determination has been performed in veterinary medicine (Monreal et al. 1993).

Production of fibrinopeptide $\mathrm{A}$ is related to thrombin activation. It is usually elevated in patients with DIC as well as in a wide variety of other micro- or macrovascular thrombotic events. The test provides an overall assessment of haemostasis activation indicating the presence of thrombin-induced fibrinogen proteolysis. Disappearance of fibrinopeptide A may aid in assessing the efficicacy of therapy in DIC (Jensen and Ens 1991).

Determination of an effective test of prothrombin activation markers $-\mathrm{F} 1+2$ fragments - was not shown to be useful in rabbits (Monreal et al. 1993).

Soluble fibrin monomer (FM) - the complex of FDPs and fibrin monomer - can be detected by protamine gelation and agglutination tests. Positive results may appear in patients with a variety of diseases which might be associated with DIC but definite proof of DIC diagnosis is still lacking. Therefore, the tests for FM are valuable mainly as broad screening tests (Slappendel 1988b). Recently, an immunological assay was developed in human medicine which can directly quantify the amount of soluble fibrin monomers (SF) formed in blood. This study examined this assay system in the diagnosis of DIC and found that it was a good indicator for both fibrin formation and for DIC. It also correlated well with serum levels of FDPs (Nakagawa et al. 1994).

\section{Fibrinolysis}

Elevated FDP concentrations are late-stage findings in most patients with DIC (Feldman 1981; Slappendel $1988 \mathrm{~b})$. FDPs are the result of plasmin biodegradation of fibrinogen or fibrin, and thus are indicative of plasmin presence in the circulation. This may be a result of primary fibrinolysis (rare in most animal species includ- ing human) or secondary as in DIC. FDP concentration results are variable and inconsistent in cats (O'Rourke et al. 1982). Canine patients with FDP concentrations of $10 \mu \mathrm{g} / \mathrm{ml}$ or more are considered to have increased fibrinolysis; the concentration may be as high as $320 \mu \mathrm{g} /$ $\mathrm{ml}$ in overt DIC patients (Slappendel 1988b). FDPs greater than $40 \mu \mathrm{g} / \mathrm{ml}$ in equine patients are only suggestive of DIC (Morris 1988). In the horse, interpreting FDP concentrations is difficult and their presence is certainly not pathognomonic for DIC.

Newer analytes for diagnosis of DIC such as quantification of B- $\beta$ 15-42 fragments and distinct fibrinogen or fibrin degradation products are widely used in human medicine, and begin to be utilised in veterinary medicine (Monreal et al. 1993). Fibrinogen degradation products (FgDP) and fibrin degradation products (FbDP) by ELISA have been suggested to be reliable and sensitive assays for diagnosis of DIC (Jensen and Ens 1991; Bick and Backer 1992). As yet, however, these analytes have not been validated for routine use in veterinary medicine. The radioimmunoassay for $\mathrm{B}-\beta$ 15-42 and related peptides, when performed in conjunction with fibrinopeptide $A$, can aid in the differential diagnosis of DIC versus primary fibrinolysis (Bick 1988; Muller 1989). B- $\beta \quad 15-42$ and related peptides result from cleavage of $B-\beta$ peptides from the $B-\beta$ chain of fibrinogen by plasmin (Fig. 2). Elevation of B- $\beta$ 15-42 and related peptides without concurrent fibrinopeptide A elevation is strong evidence for primary fibrinolysis, whereas the elevation of both is evidence of DIC (Bick 1988).

Plasminogen and $\alpha$-antiplasmin concentrations may be reduced in DIC. But enhanced fibrinolysis may be assessed by plasmin- $\alpha_{2}$-antiplasmin complex (PIC) quantification in human medicine. It has been observed

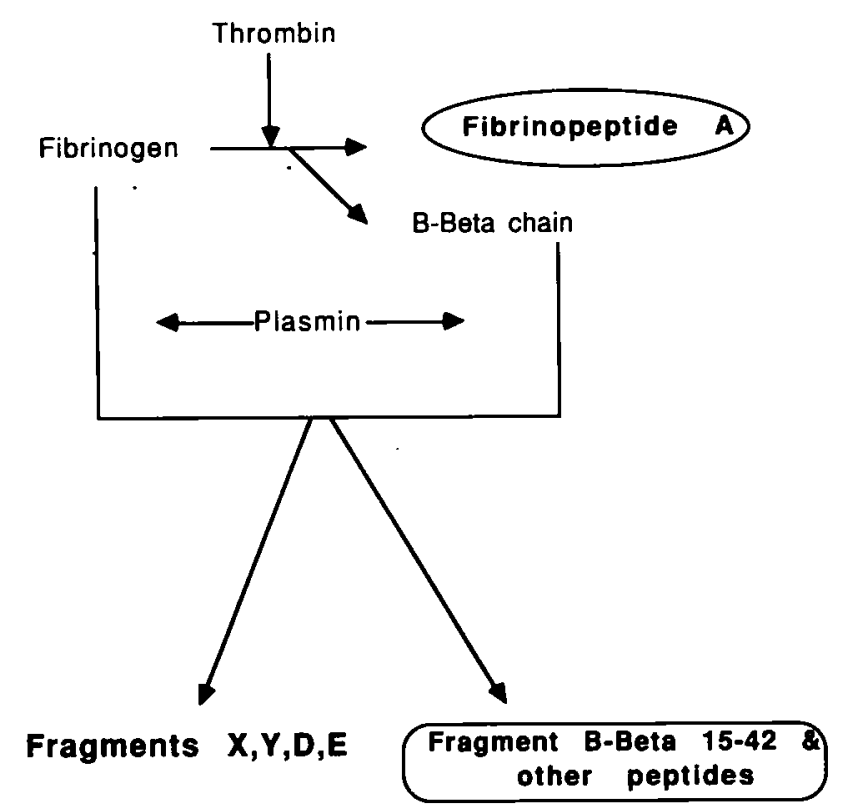

Fig. 2. Formation of fragment B-beta $15-42$ from fibrin(ogen). 
that the highest concentrations of PIC corresponded to DIC induced by acute promyelocytic leukaemia (APL), the concentrations being relatively lower than in DIC induced by sepsis.

Plasminogen activator inhibitors (PAI) are determined in human medicine. A significant elevation in active PAI was observed in DIC due to acute leukaemia, chronic myeloid leukaemia and sepsis, but not in APL, non-Hodgkin lymphoma, and cancer. Active PAI was higher in patients with multiple organ failure (MOF) than in those without MOF whereas PIC was lower in patients with this complication. Thus, the balance of coagulation and fibrinolysis varied according to the underlying cause of DIC; APL having more activation of fibrinolysis, whereas sepsis had greater activation of coagulation. It is suggested that the inhibition of secondary fibrinolytic activation plays an important role in the progression of MOF (Asakura et al. 1994).

\section{Coagulation Inhibitors}

Functional ATIII concentration in patients with DIC is commonly decreased (Tanaka et al. 1986). ATIII is a regulator of several procoagulation proteases including thrombin, factors IXa, Xa, XIa, XIIa and plasma KK (Green 1988; High 1988). Although a diagnosis of DIC can not be made from ATIII concentrations, monitoring ATIII activity is important in the management of DIC especially prior to heparin therapy and is helpful in prognosing clinical recovery (Gerhards 1987; Green 1988). Antithrombin III activity was not a useful coindicator of DIC in cats infected with feline infectious peritonitis (Boudreaux et al. 1989). This might be due to increased hepatic synthesis of ATIII and decreased catabolism secondary to diffuse vasculitis (ATIII may be rendered non-functional and thus unable to inhibit activated serine proteases) (Boudreaux et al. 1989).

Determinations of protein $\mathrm{C}$ pathway activation and contact system activation such as APC:PCI complex, $\mathrm{KK}: \mathrm{PCI}$ complex, and APC- $\alpha 1$-antitrypsin complex, have been accomplished in human medicine in relation to septic shock and early coagulation activation (Alcaraz et al. 1995). In acute malaria, reduction in plasma AT III concentrations, protein C, factor XII and prekallikrein (PK) activities were observed (Clemens et al. 1994).

\section{Fibronectin}

Fibronectin is one of the endothelial adhesion glycoprotiens which has been recently used as a molecular marker for endothelial injury (Toschi et al. 1991; Saleh et al. 1992). The concentration of fibronectin was found to be decreased in canine patients with DIC (Feldman et al. 1985).

\section{Thromboelastography}

Thromboelastography (TEG), is a less commonly available technique used to assess haemostatic function. Analysis of TEG yields qualitative information about platelet function, thromboplastin, and their interaction with the intrinsic coagulation cascade to form a stable clot. Additional information is obtained about fibrinogen and factor XIII concentrations as well as the fibrinolytic system. TEG is more sensitive and accurate than the traditional universal coagulation tests (PT, APTT) in revealing haemostatic disorders (Bigeleisen and Kang 1991). The test has also been used in diagnosis of DIC in dogs (Johnson et al. 1983).

It is not possible, as yet, to establish minimal criteria for an early diagnosis of DIC, although such criteria may clearly improve therapy and the outcome of some patients. But DIC diagnosis is frequently based on a constellation of laboratory findings, such as thrombocytopenia, hypofibrinogenaemia and high concentrations of FDPs (Mora et al. 1995), red blood cell fragmentation, thrombocytopenia, prolonged coagulation tests and increased FDPs concentrations (Chuamsumrit et al. 1993. It is also suggested that the compensated form of activation of intravascular coagulation may be diagnosed by a decrease in ATIII, an increase in TAT, the appearance of FM and D-dimers (FbDP). Prolonged bleeding time, PT, PTT and hypofibrinogenaemia are found in severe DIC (Schneider 1994).

\section{Rational Therapy}

The treatment of DIC remains controversial. There is a global perception that therapy is often futile and that most patients die. Difficulties with therapeutics in DIC are extant because of the diverse aetiologies and clinical manifestations. Simply stated, therapy should be highly individualised.

The therapy of acute DIC should be sequential and have a logical strategy (Table 4). The most important therapeutic modality is removal of the inciting cause. If the removal of the inciting cause is not possible (exemplified by widespread metastatic disease) a specific approach may be indicated (Ruehl et al. 1982). Supportive therapy must be aggressively instituted concomitant with therapy for treatment or mitigation of the underlying event.

\section{Fluid Therapy}

Fluid therapy is indicated to correct hypovolaemia, for prevention or alleviation of vascular stasis, and for dilution of thrombin, FDPs and activators of fibrinolysis (Ruehl et al. 1982). The use of electrolytes and/or volume expanders such as plasma protein fractions, albumin, dextran 70, hdyroxyethyl starch and hypertonic saline solution combined with colloids (Ruehl et 
Table 4. Sequential therapy in fulminant disseminated intravascular coagulation

1. Remove inciting cause

Use of antimicrobial or antineoplastic therapy

Control shock

Volume replacement

Glucocorticoids, antimicrobials (endotoxaemia)

2. Inhibit haemostasis

Application of heparin or

Other anticoagulant drugs (hirudin, gabexate)

Antiplatelet agents

3. 'Specific blood component therapy

Platelet concentrates - not currently applicable in veterinary medicine

Packed red cells (washed)

Antithrombin concentrates

or frozen plasma

Cryoprecipitate

4. Inhibit fibrinolysis $\left(?^{\mathrm{a}}\right)$

Epsilon-aminocaproic acid

Transexamic acid

${ }^{a}$ It is questionable if inhibition of fibrinolysis in a patient with disseminated intravascular coagulation is indicated. It may, in fact, be problematic and contraindicated.

al. 1982; Concannon et al. 1992; Zoran et al. 1992) depend upon the primary disease, blood $\mathrm{pH}$ and electrolyte and hydration status of the patient.

\section{Coagulation Inhibitors}

Heparin is the most common anticoagulant used in correction of DIC. However, it has a limited effect depending on the availability of functional patient ATIII. The anticoagulant effect of heparin is due to its ability to form complexes with plasma ATIII, potentiating the action of the complex to neutralise thrombin, factors Xa, XIIa, XIa, as well as plasmin, KK, complement and trypsin (Rosenberg 1975; Green 1988). Administration of high-dose heparin may increase the risk of haemorrhage in patients with acute DIC. Heparin therapy can be successful in compensated DIC when functional ATIII concentrations are available (Ruehl et al. 1982). Transfusion of fresh plasma would provide ATIII and other serine protease inhibitors and subsequent administration of low doses of heparin may sustain appropriate haemostasis (Wisecarver and Haire 1989; Welch et al. 1992). Heparin may be added to the container of fresh frozen plasma and incubated, to ensure a continuous ATIII infusion and avoiding ATIII depletion (Feldman 1990). Low-molecular-weight heparins (LMWH) are obtained from standard heparin. They have greater inhibitory effects on factor Xa than on thrombin, less interaction with platelets, and may have potentially new therapeutic applications (Samama and Babinet 1991). Their mode of action on the haemostatic system is based in their anti-factor $\mathrm{Xa}$ and IIa
ATIII-dependent activity. Preliminary studies indicated that LMWH are effective in treatment of DIC and have less risk of haemorrhage (Oguma et al. 1990). Recently, it has been observed that administration of LMWH to horses may avoid some undesirable effects related to standard heparin administration, such as erythrocyte agglutination (Monreal et al. 1995).

Newer agents with potential therapeutic benefits for fulminant and compensated DIC are recombinant hirudin and gabexate mesilate (Hauptmann and Bruggener 1988; Umeki et al. 1988). These drugs are capable of inhibiting thrombin or factor $\mathrm{Xa}$ in the absence of ATIII. Experimental studies proved that hirudin (Nowak and Markwardt 1991) and gabexate mesilate (Suzuki et al. 1988) inhibit different triggering mechanisms for DIC induced by endotoxins. Further studies in the use of these products in veterinary medicine might affect morbidity and mortality from endotoxin-induced DIC. An orally active new specific inhibitor of factor Xa, DX-9065a, has been studied against two kinds of experimental DIC in rats (Yamazaki et al. 1994).

\section{Antiplatelet Aggregant Therapy}

This has been used in patients with compensated DIC (Ruehl et al. 1982; Morris 1988; Slappendel 1988b). Acetylsalicylic acid inhibits platelet aggregation and blocks TxA 2 release (Yao et al. 1991). However, platelet inhibitors should not be used in patients with severe thrombocytopenia (Ruehl et al. 1982).

\section{Blood Product Therapy}

This is indicated if haemorrhage occurs. This form of therapy necessitates the ability to continually assess the patient's haemostatic system. The severity of blood loss, thrombocytopenia, hypofibrinogenaemia, and coagulopathy, indicates the selection of blood products. Packed red cells, platelet concentrates, platelet rich plasma, fresh frozen plasma, cryoprecipitate, or fresh whole blood may be considered (Mora et al. 1955). In patients that appear to be clinically stable, administration of fresh or stored frozen plasma or cryoprecipitate may be indicated. It has been proposed that administration of blood products to a patient with ongoing DIC and microvascular thrombosis carries the risk of plasmin biodegradation of the administered coagulation factors (Bick et al. 1976; Bick 1988). Experimental administration of recombinant human activated protein $\mathrm{C}$ has also been studied in tissue thromboplastin-induced disseminated intravascular coagulation (DIC) in rabbits (Katsura et al. 1994). The use of ATIII concentrates in human medicine is not thoroughly discussed in relation to the clinical improvement observed (Lechner and Kyrle 1995) ' . . . the doses [of ATIII] applied in adult intensive care patients with septicaemia does not appear to improve outcome in terms of mortality' (van Beek et al. 1994). 


\section{Fibrinolytic Inhibitors}

Fibrinolytic inhibitors are rarely indicated, unless secondary fibrinolysis continues to biodegrade plasma proteins. If this occurs, antifibrinolytic ( $\epsilon$-aminocaproic acid) therapy may be considered. It is, however, important to note that this therapy is contraindicated for patients with ongoing DIC, as these patients are dependent on fibrinolysis to clear microthrombi. Also antifibrinolytic therapy should never be applied unless increased fibrinolytic activity and subsequent haemorrhage have been documented. Tranexamic acid has recently been used as a potent antifibrinolytic agent (Takada et al. 1990).

For effective therapy of DIC and to avoid complicating the existing condition, therapy should be monitored. Return of fibrinogen concentration, ATIII concentration, platelet numbers, and PT and APTT towards reference intervals are among the most consistent signals of therapeutic success. It should be noted that this statement is in direct opposition to the myth of prolonging the universal tests of coagulation (PT and APTT) towards some predetermined time.

Finally, preventive measures to reduce morbidity and mortality from endotoxaemia-induced DIC in horses have been studied. Studies involved feeding horses a diet enriched with $\Omega-3$ fatty acids. These fatty acids alter the cell-membrane phospholipid composition. Results indicated that mononulcear phagocytes from horses on this diet have reduced ability to produce inflammatory mediators including eicosanoids and TNF, in response to endotoxins in vitro (Henry et al. 1991; Morris et al. 1991).

\section{References}

Alcaraz A, España F, Sánchez-Cuenca J et al. (1995) Activation of the protein $C$ pathway in acute sepsis. Thromb Res 79:83-93

Ampel LL, Marshall S, Caprini JA (1985) Etiology, diagnosis, and treatment of recovery room bleeding/hemorrhage. Heart Lung 14:556-561

Anderson KL, Smith LA, DeGraves FJ et al. (1992) Polymorphonuclear neutrophil leukocyte function in clinical bovine patients and in cows with or without Staphylococcus aureus mastitis. Vet Res Commun 16:107-115

Angelov A (1989) Intravascular coagulation in relation to pregnancy and delivery. Zentralbl Gynäkol 111:1169-1175

Asakura H, Jokaji H, Saito M et al. (1991) The course of disseminated intravascular coagulation is predicted by changes in thrombinantithrombin III complex levels - is there any difference between treatment with standard heparin or low-molecular-weight heparin? Blood Coagul Fibrinolysis 2:623-627

Asakura H, Jokaji H, Saito M et al. (1994) Study of the balance between coagulation and fibrinolysis in disseminated intravascular coagulation using molecular markers. Blood Coagul and Fibrinolysis 5:829-832

Axelsson L, Bergenfeldt M, Bjork P et al. (1990) Release of immunoreactive canine leukocyte elastase normally and in endotoxin and pancreatitis shock. Scand J Clin Lab Invest 50:35-42

Badenoch JP, Ramshaw IA, Grant A (1986) Cellular and secreted tumor plasminogen activator: the effects of $\mathrm{NaCl}$. Experientia 42:433-435

Baker WF (1989) Clinical aspects of disseminated intravascular coagulation: a clinician's point of view. Semin Thromb Hemost 15:1-43

Baker DC, Green RA (1987) Coagulation defects of aflatoxin intoxicated rabbits. Vet Pathol 24:62-70

Barnett AH (1991) Pathogenesis of diabetic microangiopathy: an overview. Am J Med 90:675-735

Bick RL (1979) Vascular disorders associated with thrombohemorrhagic phenomena. Semin Thromb Hemost 5:167-183

Bick RL (1982) Disseminated intravascular coagulation: clinical/ laboratory correlation. Am J Clin Pathol 77:244-253

Bick RL (1985) Disorders of hemostasis and thrombosis. Thieme, New York, pp 157-204

Bick RL (1988) Disseminated intravascular coagulation and related syndromes: a clinical review. Semin Thromb Hemost 14:299-338

Bick RL, Baker WF (1992) Diagnostic efficacy of the D-dimer assay in disseminated intravascular coagulation (DIC). Thromb Res 65:785-790

Bick RL, Schmalhorst WR, Fekete LF (1976) Disseminated intravascular coagulation and blood component therapy. Transfusion $16: 361-376$

Bigeleisen PE, Kang Y (1991) Thromboelastography as an aid to regional anesthesia: preliminary communication. Reg Anaesth 16:59-61

Blood DC, Radostits OM (1989) Veterinary medicine. Bailliere Tindall, London, pp 984-992

Borrego D, Maria TP, Cascales P et al. (1991) Massive intravascular hemolysis in septicemia caused by Clostridium perfringens. Sangre 36:315-317

Bosner H, Pavesic D, Masovcic J et al. (1989) Acute renal failure following necrosis of a myoma in the puerperium. Jugosl Ginekol Perinatol 29:55-58

Boudreaux MK, Weiss RC, Cox $\mathrm{N}$ et al. (1989) Evaluation of antithrombin-III activity as a coindicator of disseminated intravascular coagulation in cats with induced feline infectious peritonitis virus infection. Am J Vet Res 50:1910-1913

Bowersock TL, Walker RD, Maddux JM et al. (1990) Hematological changes in calves exposed to a mixture of lipopolysaccharide and crude leukotoxin of Pasteurella haemolytica. Can J Vet Res 54:415421

Braun U, Bearth G, Dieth V et al. (1990) A case of disseminated intravascular coagulation (DIC) in a cow with endometritis and fetal death. Schweiz Arch Tierheilkd 132:239-245

Buntain B (1980) Disseminated intravascular coagulopathy (DIC) in a cow with left displaced abomasum, metritis, and mastitis. Agri Pract 1023-1026

Camiolo SM, Greco WR (1986) Plasminogen activator content of human tumor and adjacent normal tissue measured with fibrin and non-fibrin assays. Cancer Res 46:1788-1794

Carlson GP (1990) Diseases of the hematopoietic and hemolymphatic systems. In: Smith PB (ed) Large animal medicine. CV Mosby, Philadelphia, pp 1068-1082

Carroll RC, Rubinstein E, Worthington RE et al. (1990) Extensive Clq-complement initiated lysis of human platelets by IgG subclass murine monoclonal antibodies to the $\mathrm{CD} 9$ antigen. Thromb Res 59:831-839

Chuamsumrit kA, Hotrakitya S, Hathirat P et al. (1993) Disseminated intravascular coagulation in children: diagnosis, management and outcome. Southeast Asian J Trop Med Public Health 24 Suppl $1: 229-233$

Clauss M, Murray JC, Vianna M et al. (1990) A polypeptide factor produced by fibrosarcoma cells that induces endothelial tissue factor and ehnhances the procoagulant rsponse to tumor necrosis factor/cachectin. J Biol Chem 265:7078-7083

Clemens R, Pramoolsinsap C, Lorenz R et al. (1994) Activation of the coagulation cascade in severe falciparum malaria through the intrinsic pathway. $\mathrm{Br} \mathrm{J}$ Haematol 87:100-105

Clouse LH, Comp PC (1986) The regulation of hemostasis: the protein C system, N Engl J Med 314:1298-1304

Concannon KT, Haskins SC, Feldman BF (1992) Hemostatic defects associated with two infusion rates of dextran 70 in dogs. Am J Vet Res 53:1369-1375

Cooley AJ, Clemmons RM, Gross TL (1987) Heartworm disease 
manifested by encophalomyelitis and myositis in a dog. J AM Vet Med Assoc 190:431-432

Cosgriff TM (1989) Viruses and hemostasis. Rev Infect Dis 11 Suppl 4:S672-688

Cotter SM (1992) Hematological emergencies and transfusion medicine. Proc Am Anim Hosp Assoc (59th annual meeting, New Orleans, Louisiana) pp 78-80

Cowell AK, Cowell. RL, Tyler RD et al. (1991) Severe systematic reactions to Hymenoptera stings in three dogs. J Am Vet Med Assoc 198:1014-1416

Daugschies A, Altfeld E, Rommel M (1989) Hemostatic alterations in pigs fed sublethal doses of Sarcocystis miescheriana. Vet Parasitol $34: 1-13$

Dillon AR, Braund KG (1982) distal polyneuropathy after canine heartworm disease therapy complicated by disseminated intravascular coagulation. J Am Vet Med Assoc 181:239-242

Dodds WJ (1985) Blood dyscrasias affecting the surgical patienthemostatic and thrombotic disorders. In: Slatter DH (ed) Textbook of small animal surgery. WB Saunders, Philadelphia, pp 1184-1194

Drazner FH (1982) Clinical implication of disseminated intravascular coagulation. Comp Cont Ed Vet Pract 4:974-891

Duffy MJ (1990) Plasminogen activators and cancer. Blood Coagul Fibrinolysis 1:681-687

Edwards RL, Morgan DL, Rickles FR (1990) Animal tumor procoagulants: registry of the Subcommittee on Haemostasis and Malignancy of the Scientific and Standardization Committee, International Society of Thrombosis and Hameostasis. Thromb Haemost 63:133-138

Ellison GW, King RR, Calderwood MM (1988) Medical and surgical management of multiple organ infarctions secondary to bacterial endocarditis in a dog. J Am Vet Med Assoc 193:1289-1291

Edmond CT (1994) Possible involvement of cytokines in diffuse intravascular coagulation and thrombosis. Baillieres Clin Hameatol $7: 453-468$

Ewert KM, Fessler JF, Templeton CB et al. (1985) Endotoxininduced hematologic and blood chemical changes in ponies: effect of flunixin meglumine, dexamethasone, and prednisolone. Am J Vet Res 46:24-30

Feldman BF (1981) Disseminated intravascular coagulation. Comp Cont Ed Vet Pract 3:45-52

Feldman BF (1990) Disseminated Intravascular Coagulation (DIC) Disseminated Intravascular Thrombosis (DIT) Consumption Coagulopathy (CC). In: Proceedings of Second International Veterinary Emergency and Critical Care Symposium, San Antonio, Texas

Feldman BF, Madewell BR, O'Neill S (1981) Disseminated intravascular coagulation: antithrombin, plasminogen, and coagulation abnormalities in 41 dogs. J Am Vet Med Assoc 179:151-154

Feldman BF, Thomason KJ, Jain NC (1988) Quantitative platelet disorders. Vet Clin North Am Small Anim Pract 18:35-49

Feldman BF, Thomson DB, O'Neill S (1985) Plasma fibronectin concentrations in dogs with disseminated intravascular coagulation. Am J Vet Res 46:1171-1174

Frelier PF, Lewis RM (1984) Hematologic and coagulation abnormalities in acute bovine sarcocystosis. Am J Vet Res 45:40-48

Gentry PA, Feldman BF, Liptrap RM (1991) Haemostasis and parturition re-visited; comparative profiles in mammals. Comp Haematol Int 1:150-154

Gerhards H (1987) Antithrombin III determination in horses. Reference values and acquired antithrombin III deficiency, Tierarztl Prax 15:47-55

Giger U, Gorman NT (1984) Oncologic emergencies in small animals. Part 1. Chemotherapy related and hematologic emergencies. Comp Cont Ed Pract Vet 6:689-698

Goodwin-MN (1989) Selected anatomic burn pathology review for clinicians and pathologists. Aviat Space Environ Med 60:B39-43

Gordon SG (1984) Evidence of a tumor proteinase in blood coagulation. In: Honn KV, Sloane BF (eds) Hemostatic mechanisms and metastasis. Martinus Nijhoff, Boston, pp 72-83

Green RA (1981) Hemostasis and disorders of coagulation. Vet Clin North Am Small Anim Pract 11:289-317

Green RA (1988) Pathophysiology of antithrombin III deficiency. Vet Clin North Am Small Anim Pract 18:95-104
Green RA (1989) Hemostatic disorders: coagulopathies and thrombotic disorders. In: Ettinger SJ (ed) Textbook of veterinary internal medicine. WB Saunders, Philadelphia, pp 2246-2264

Greene CE (1990) Infectious canine hepatitis and canine acidophil cell hepatitis. In: Green CE (ed) Infectious diseases of the dog and cat. WB Saunders, Philadelphia pp 242-244

Greene CE, Scott FW (1990) Feline panleukopenia. In: Greene CE (ed) Infectious diseases of the dog and cat. WB Saunders, Philadelphia, pp 291-299

Hagiwara MK, Kogika MM, Maluceli BE (1990) Disseminated intravascular coagulation in dogs with aflatoxicosis. J Small Anim Pract 31:239-243

Hall DE (1972) Blood coagulation and its disorders in the dog. Williams \& Wilkins, Baltimore, pp 109-128

Hammer AS, Couto CG, Swardson C et al. (1991) Hemostatic abnormalities in dogs with hemangiosarcoma. J Vet Intern Med 5:11-14

Hardaway RM (1980a) Mechanism of traumatic shock. Surg Gynecol Obstet 151:65-69

Hardaway RM (1980b) Influence of fibrinogen levels in dogs on mortality from hemorrhagic and traumatic shock. J Trauma 20:417419

Hardaway RM (1981) Prediction of survival or death of patients in a state of severe shock. Surg Gynecol Obstet 152:200-206

Hardaway RM, Williams CH (1987) Influence of steroids on hemorrhagic and traumatic shock. J Trauma 27:667-670

Hardaway RM, Williams CH (1990) A new treatment for traumatic shock and ARDS. Resuscitation 19:61-76

Hargis AM, Feldman BF (1991) Evaluation of hemostatic defects secondary to vascular tumors in dogs: 11 cases (1983-1988). J Am Vet Med Assoc 198:891-894

Hauptmann J, Bruggener E (1988) Influence of hiridun on the consumption of antithrombin III in experimental DIC. Folia Haematol Leipz 115:83-87

Helfand SC (1988) Platelets and neoplasia. Vet Clin North Am Small Anim Pract 18:131-135

Henry MM, Moore JN, Fischer JK (1991) Influence of an omega-3 fatty acid-enriched ration on in vivo responses of horses to endotoxin. Am J Vet Res 52:523-527

Hersch SL, Kunelis T, Francis RB (1987) The pathogenesis of accelerated fibrinolysis in liver cirrhosis: a critical role for tissue plasminogen activator inhibitors. Blood 69:1315-1319

High KA (1988) Antithrombin III, protein C, and protein S. Naturally occurring anticoagulant proteins. Arch Pathol Lab Med 112:28-36

Holland M, Kelly AB, Synder JR (1986) Antithrombin III activity in horses with large colon torsion. Am J Vet Res 47:897-900

Holman ND, Schneider AJ (1989) Multi-organ damage in exertional heat stroke. Neth J Med 35:38-43

Howerth EW, Greene CE, Prestwood AK (1988) Experimentally induced bluetongue virus infection in white-tailed deer: coagulation, clinical pathologic, and gross pathologic changes. Am J Vet Res 49:1906-1913

Huang HB (1991) Vaccination against and immune response to viral haemorrhagic disease of rabbits: a review of research in the People's Republic of China. Rev Sci Tech 10:481-498

Iashvili BP, Baluda VP, Lukhoyanova TI et al. (1986) The effects of administration of drugs influencing during treatment of patients with burns. Burns Incl Therm Inj 12:184-187

Irimura T, McIsaac AM, Carlson DA et al. (1990) Soluble factor in normal tissues that stimulates high-molecular-weight sialoglycoprotein production by human colon carcinoma cells. Cancer Res 50:3331-3338

Isogai $\mathrm{E}$, Isogai $\mathrm{H}$, Onuma $\mathrm{M}$ et al. (1989) Escherichia coli associated endotoxemia in dogs with parvovirus infection. Jpn $J$ Vet Sci 51:597-606

Jacobse-Geels HEL, Daha MR, Horzinek MC (1980) Isolation and characterization of feline $\mathrm{C} 3$ and evidence for the immune complex pathogenesis of feline infectious peritonitis. I Immunol 125:16061610

Jandl JH (1991) Blood: pathophysiology. Blackwell Scientific Publications, Boston, pp 510-533

Jensen R, Ens GE (1991) Diagnostic application of thrombotic markers. Clin Hemost Rev 5:1-7 
Johnson JT, Zuckerman L, Dunkin PG et al. (1983) Thromboelastography used to monitor a dog with disseminated intravascular coagulation. J Am Anim Hosp Assoc 19:182-186

Johnstone DE (1985) Burns, electrical, chemical and cold injuries. In: Slatter DH (ed) Textbook of small animal surgery. WB Saunders, Philadlephia, p 510-533

Johnstone IB, Crane S (1986) Hemostatic abnormalities in equine colic. Am J Vet Res 47:356-358

Jones DRE, Gruffydd JTJ, McCullagh KG (1980) Disseminated intravascular coagulation in a dog with thoracic neoplasia. J Small Anim Pract 21:303-309

Kapina MA, Zelenin MG, Egorov BB (1986) Screening of human and animal tissue cell cultures as potential producers of plasminogen activator. Antibiot Med Biotekhnol 31:756-760

Kaplank AP, Silverberg M (1987) The coagulation-kinin pathway of human plasma. Blood 70:1-15

Katsuura Y, Aoki K, Tanabe H et al. (1994) Characteristic effects of activated human protein $\mathrm{C}$ on tissue thromboplastin-induced disseminated intravascular coagulation in rabbits. Thromb Res 76:353-362

Kiper ML, Paulsen DP (1988) Acute mastitis and disseminated intravascular coagulopathy caused by Pasteurella haemolytica in a cow. J Am Vet Med Assoc 192:205-206

Kobilinsky L, Hardy WD, Day NK (1979) Hypocomplementemia associated with naturally occurring lymphosarcoma in pet cats. $\mathrm{J}$ Immunol 122:1239-1242

Kociba GJ, Hathaway JE (1974) Disseminated intravascular coagulation associated with heartworm disease in the dog. J Am Anim Hosp Assoc. 10:373-378

Kokosharov T, Khristov KH, Nikolov N (1990) Disseminated intravascular coagulation in fowls after experimentally induced acute salmonellosis. Vet Sbirka 88:28-31

Krooshof Y, Hellebrekers LJ, Feldman BF (1984) Two cases of combined babesiosis and ehrlichiosis in dogs. Canine Pract 11:1216

Kubota T, Andoh K, Sadakata $\mathrm{H}$ et al. (1991) Tissue factor released from leukemic cells. Thromb Haemost 65:59-63

Lechner K, Kyrle PA (1995) Antithrobin III concentrates - are they clinically useful? Thromb Haemost 73:340-348

Lefrere JJ Conard J, Lerable J et al. (1989) Antithrombin III and hepatocellular carcinoma. Thromb Haemost 62:817

Lipowitz AJ (1985) Surgical complications. In: Slatter DH (ed) Textbook of small animal surgery. WB Saunders, Philadelphia, pp 165-171

Lippincott CL, Schulman AJ (1989) Gastric dilatation volvulus-torsin syndrome. In: Ettinger SJ (ed) Textbook of veterinary internal medicine. WB Saunders, Philadelphia, pp 1278-1288

Lockwood CJ, Bach R, Ghuha A et al. (1991) Amniotic fluid contains tissue factor, a potent initiator of coagulation. Am J Obstet Gynecol 165:1335-1341

Madewell BR, Feldman BF (1980) Characterization of anemias associated with neoplasia in small animals. J Am Vet Med Assoc 176:419-425

Mant MJ, King EG (1979) Severe, acute disseminated intravascular coagulation. A reappraisal of its pathophysiology, clinical significance and therapy, based on 47 patients. Am J Med 67:559

Masci PP, Rowe EA, Whitaker AN et al. (1990) Fibrinolysis as a feature of disseminated intravascular coagulation (DIC) after Pseudonaja textilis textilis envenomation. Thromb Res 59:859-870

McClure JR, McClure JJ (1982) Intravascular coagulopathies associated with alimentary-induced acute laminitis in the pony. In: Proceedings of the first equine endotoxemia-laminitis symposium, (Colden, Colorado, American Association of Equine Practitioners) pp 124-127

McKay DG (1983) Clinical significance of intravascular coagulation. Bibl Haematol 49:63

Mohanty D, Ghosh K, Das KC (1991) Studies on the mechanism of synthesis and release of the procoagulant activity from leukaemic cells. Med Oncol Tumor Pharmacother 8:15-21

Moher DF (1988) Disorders of blood coagulation. In: Wyngaarden JB, Smith LN (eds), Cecil textbook of medicine. WB Saunders, Philadelphia, pp 1060-1081

Monreal L, Anglés AM, Ruiz de Gopegui R et al. (1993) Valores normales de los parámetros hematológicos y hemostáticos en el conejo. Determinación de nuevos parámetros para modelos experimentales de trombosis y hemostasia. Sangre 38:365-369

Monreal $L$, Villatoro AJ, Monreal $M$ et al. A comparison of the effects of Low-Molecular Weight and Unfractionated Heparin in horses. Am J Vet Res 56,10:1281-1289

Mora A, Cortés C, Roige J et al. (1995) Trasplante hepático ortotópico por hemangioma cavernoso gigante y síndrome de Kasabach-Merritt. Rev Esp Anestesiol Reanim 42:71-74

Morris DD (1988) Recognition and management of disseminated intravascular coagulation in horses. Vet Clin North Am Equine Pract 4:115-143

Morris DD (1991) Endotoxemia in horses. A review of cellular and humoral mediators involved in its pathogenesis. J Vet Intern Med 5:167-181

Morris DD, Henry MM, Moore JN et al. (1991) Effect of dietary alpha-lineolenic acid on endotoxin-induced production of tumor necrosis factor by peritoneal macrophages in horses. Am J Vet Res 52:528-532

Muller BG (1989) Pathophysiologic and biochemical events in disseminated intravascular coagulation: dysregulation of procoagulant and anticoagulant pathways. Semin Thromb Hemost 15:58-87

Murano G, Bick RL (1980) Basic concepts of hemostasis and thrombosis. CRC Press, Boca Raton, pp 43-78

Nakagawa K, Tsuji H, Masuda H et al. (1994) Plasma levels of soluble fibrin in patients with malignancy-associated disseminated intravascular coagulation. Blood Coagul Fibrinolysis 5:725-730

Nakamura S, Shimokama T, Yoshikawa Y et al. (1990) Immune complex-induced disseminated intravascular coagulation (DIC). An experimental study. Acta Pathol Jpn 40:476-485

Nguyen P, Petitfrere E, Potron G (1995) Mechanisms of the platelet aggregation induced by activated neutrophils and inhibitory effect of specific PAF receptor agonists. Thromb Res 78:33-42

Nomura S, Nagata H, Suzuki M et al. (1991) Microparticle generation during in vitro platelet activation by anti-CD9 murine monoclonal antibodies. Thromb Res 62:429-439

Nowak G, Markwardt F (1991) Hirudin in disseminated intravascular coagulation. Haemostasis. 21 Suppl 1:142-148

Oguma Y, Sakuragawa N, Maki M et al. (1990) Treatment of disseminated intravascular coagulation with low molecular weight heparin. Research Group of FR-860 on DIC in Japan. Semin Thromb Hemost 16: 34-40

O'Keefe DA, Couto CG (1988) Coagulation abnormalities associated with neoplasia. Vet Clin north Am Small Anim Pract 18:157-168

Olubayo RO, Mugera GM (1985) Pathogenesis of haemorrhages in Trypanosoma vivax infection in cattle. 1. Disseminated intravascular coagulation. Bull Anim Heal Prod Africa 33:211-217

Ono I (1987) Alteration in coagulation and fibrinolysis after burn injury and significance of anticoagulation therapy using heparin and antithrombin III concentrate. Hokkaido Igaku Zasshi 62:108-121

Ordog GJ, Wasserberger J (1986) Coagulation abnormalities in traumatic shock. Crit Care Med 14:519-523

O'Rourke L, Feldman BF, Ito RK (1982) coagulation, fibrinolysis, and kinin generation in adult cats. Am J Vet Res 43:1478-1489

Papinger I (1986) Clinical relevance of protein C. Blut 53:63-75

Pan IC, Whyard TC, Hess WR et al. (1988) Epitopic diversity of African swine fever virus. Virus Res 9:93-106

Parihar MS, Kailashi SC, Pandey AK (1991) A comparison study of phospholipids in human, goat and chick amniotic fiuid. Biomed Biochem Acta 50:955-958

Peterson LC, Valentin S, Hedner, U (1995) Regulation of extrinsic pathway system in health and disease: the role of factor VIla and Tissue Factor Pathway Inhibitor. Thromb Res 79:1-35

Radomski MW, Jenkins DC, Holmes L et al. (1991) Human colorectal adenocarcinoma cells: differential nitric oxide synthesis determines their ability to aggregate platelets. Cancer Res 51:60736078

Raphael BG (1982) Disseminated intravascular coagulation during surgery for scoliosis. Clin Orthop 162:41-46

Rebar AH, Hahn FF, Halliwell WH (1980) Microangiopathic hemolytic anemia associated with radiation-induced hemangiosarcomas. Vet Pathol 17:443-454

Reilly D, Andreasen PA, Duffy MJ (1991) Urokinase-plasminogen 
activator in breast cancer: assay by both catalytic and immunoassay. Blood Coagul Fibrinolysis 2:47-50

Roncaglioni MC, Falanga A, D'Alessandro AP et al. (1989) Evidence of a warfarin-sensitive cancer procoagulant in V2 carcinoma. Haematologica 74:143-147

Rosenberg RD (1975) Actions and interactions of antithrombin and heparin. N Engl J Med 292:146-151

Ruehl W, Mills C, Feldman BF (1982) Rational therapy in disseminated intravascular coagulation. J Am Vet Med Assoc 181:76-78

Saleh AA, Bottoms SF, Farag AM et al. (1992) Markers for endothelial injury, clotting and platelet activation in preeclampsia. Arch Gynecol Obstet 51:105-110

Samama M, Babinet BA (1992) The new heparins. J Mal Vasc 17:91106

Sandberg H, Bode AP, Dombrose FA et al. (1985) Expression of coagulant activity in human platelets: release of membranous vesicles providing platelet factor 1 and platelet factor 3 . Thromb Res 39:63-79

Schaeffer RC, Briston C, Chilton SM et al. (1986) Disseminated intravascular coagulation following Echis carinatus venom in dogs: effects of a synthetic thrombin inhibitor. J Lab Clin Med 107:488497

Schneider H (1994) Leberpathologie im Rahmen des HELLPSyndroms. Arch Gynecol Obstet 255 Suppl 2:S245-254

Schrier SL (1993) Disorders of hemostasis and coagulation. In: Rubinstein E, Federman DD (eds) Scientific American medicine. New York, Scientific American, vol 5 pp 1-59

Seegers WH (1971) Use and regulation of blood clotting mechanisms. In: Seegers WH (ed) Blood clotting enzymology, Academic Press, New York, $p 1$

Slappendel RJ (1988a) disseminated intravascular coagulation associated with neoplasia. Vet Clin North Am Small Anim Pract 18:271-273

Slappendel RJ (1988b) Disseminated intravascular coagulation. Vet Clin North Am Small Anim Pract 18:169-184

Spearman MA, Ballon BC, Gerrard JM et al. (1991) The inhibition of platelet aggregation of metastatic H-ras-transformed 10T1/2 fibroblasts with castanospermine, an $\mathrm{N}$-linked glycoprotein processing inhibitor. Cancer Lett 60:185-191

Stein DS, Libertin CR (1990) Disseminated intravascular coagulation in association with cavitary tuberculosis. South Med J 83:60-63 Studdert MJ (1994) Rabbit haemorrhagic disease virus: a calicivirus with differences. Aust Vet J 71:264-264

Suchartwatnachai C, Linasmita V, Chaturachinda K (1991) Obstetric hysterectomy: Ramathibodi's experience 1969-1987. Int J Gynaecol Obstet 36:183-186

Suliman HB, Feldman BF (1989) Pathogenesis and aetiology of anaemia in trypanosomiasis with special reference to $T$. bruce $i$ and T. evansi. Vet Bull 59:99-107

Suzuki M, Suematsu M, Miura S et al. (1988) Microcirculatory disturbances in endotoxin-induced disseminated intravascular coagulation. The effects of heparin and gabexate mesilate on locomotive and metabolic changes of neutrophils. Adv Exp Med Biol 242:135-141

Takada A, Takada Y, Mori T et al. (1990) Prevention of severe bleeding by tranexamic acid in a patient with disseminated intravascular coagulation. Thromb Res 58:101-108

Tanaka H, Kobayashi N, Maekawa T (1986) Studies on production of antithrombin II with special reference to endotoxin-induced DIC in dogs. Thromb Haemost 56:137-143

Taylor FB Jr (1994) Studies on the inflammatory-coagulant axis in the baboon response to $E$. coll: regulatory roles of proteins $C, S$, C4bBP and of inhibitors of tissue factor. Prog Clin Biol Res 388:175-194

Titova SI, Kozlov GI, Mamedgasanov RM (1989) Disorders of blood coagulation and microcirculation in diabetics. Probl Endokrinol Mosk 35:3-7

Toschi V, Fiorini GF, Motta A et al. (1991) Clinical significance of endothelial damage markers in essential mixed cryoglobulinemia. Acta Haematol 86:90-94

Uehara S, Honjyo K, Furukawa S et al. (1989) Role of the kallikreinkinin system in human pancreatitis. Adv Exp Med Biol 247B:643648

Ueyama M, Yamamoto I, Sawada Y (1991) Disseminated intravascular coagulation in the early stage after severe burn: the role of excessive thrombin generation. Nippon Geka Gakkai Zasshi 92:907-912

Umeki S, Adachi M, Watanabe $\mathrm{M}$ et al. (1988) Gabexate as a therapy for disseminated intravascular coagulation. Arch Intern Med 148:1409-1412

Van Beek EJ, von der Mohlen MA, ten Cate JW et al. (1994) Antithrombin III concentrate in the treatment of DIC: a retrospective follow-up study. Neth J Med 45:206-210

Venturini CM, Kaplan JE (1992) Thrombin induces platelet adhesion to endothelial cells. Semin Thromb Hemost 18:275-283

Wachtfogel YT, de la Cadena R, Colman R (1993) Structural biology, cellular interactions and pathophisiology of the contact system. Thromb Res 72:1-21

Wagner DS, Klein RL, Robinson HB et al. (1990) Placental emboli from a fetus papyraceousm. J Pediatr Surg 25:538-542

Walsh LJ, Trincheri G, Waldorf HA et al. (1991) Human dermal mast cells contain and release tumor necrosis factor $\alpha$, which induces endothelial leukocyte adhesion molecule E. Proc Nat Acad Sci USA 88:4220-4224

Ward MV, Conway DL (1980) A severe case of acute suppurative dermatitis with disseminated intravascular coagulation in a dog. Vet Med Small Anim Clin 75:1564-1568

Warr TA, Rao LV, Rapaport-SI (1990) Disseminated intravascular coagulation in rabbits induced by administration of endotoxin or tissue factor: effect of anti-tissue factor antibodies and measurement of plasma extrinsic pathway inhibitor activity. Blood 75:14811489

Welch RD, Watkins JP, Taylor TS et al. (1992) Disseminated intravascular coagulation associated with colic in 23 horses (1984 1989). J Vet Intern Med 6:29-35

Williams DA (1989) Exocrine pancreatic disease. In Ettinger SJ (ed) Textbook of veterinary internal medicine. WB Saunders, Philadelphia, pp 1520-1554

Wintrobe MW, Lee GR, Boggs DR et al, (1981) Clinical hematology. Lea \& Febiger, Philadelphia, pp 104-162

Wisecarver JL, Haire WD (1989) Disseminated intravascular coagulation with multiple arterial thromboses responding to antithrombin-III concentrate infusion. Thromb Res 54:709-717

Wu HF, Lundblad RL, Church FC (1995) Neutralization of heparin activity by neutrophil lactoferrin. Blood 85:421-428

Yamazaki M, Asakura H, Aoshima K et al. (1994) Effects of DX$9065 \mathrm{a}$, an orally active, newly synthesized and specific inhibitor of factor $\mathrm{Xa}$, against experimental disseminated intravascular coagulation in rats. Thromb Haemost 72:392-396

Yao SK, Benedict CR, Rosolowsky M et al. (1991) Effect of aspirin on local prostaglandin production and serotonin accumulation in a canine model with coronary cyclic flow variatins or thrombosis. J Mol Cell Cardiol 23:473-482

Zoran DL, Jergens AE, Riedesel DH et al. (1992) Evaluation of hemostatic analytes after use of hypertonic saline solution combined with colloids for resuscitation of dogs with hypovolemia. Am J Vet Res 53:1791-1796 